\title{
Molecular Characterization of Mulberry Accessions in Turkey by AFLP Markers
}

\author{
Salih Kafkas ${ }^{1}$ \\ Department of Horticulture, Faculty of Agriculture, University of Çukurova, 01330, Adana, Turkey \\ Mustafa Özgen \\ Department of Horticulture, Gaziosmanpaşa University, Tokat, Turkey 60240
}

Yıldız Doğan and Burcu Özcan

Department of Horticulture, Faculty of Agriculture, University of Çukurova, 01330, Adana, Turkey

Sezai Ercişli

Department of Horticulture, Faculty of Agriculture, Ataturk University 25240 Erzurum, Turkey

\author{
Sedat Serçe \\ Department of Horticulture, Mustafa Kemal University, Antakya, Hatay, Turkey 31034
}

AdDitional Index words. Morus alba, Morun nigra, Morus rubra, molecular markers, capillary electrophoresis

\begin{abstract}
Mulberries (Morus L.) show a great deal of genetic variability and adaptability to various environments. There are more than $\mathbf{2 4}$ species of mulberries in cultivated and wild forms. In Turkey, three Morus species, M. alba L., M. nigra L., and M. rubra L., are grown. In this study, we attempted to characterize 43 Morus accessions originating from distinct regions of Turkey using fluorescent dye amplified fragment length polymorphism (AFLP) markers and capillary electrophoresis. The accessions belonged to $M$. alba, M. nigra, and M. rubra; $M$. alba consisted of white- and purple-fruited samples. Eight primer combinations generated a total of 416 bands, 337 of which were polymorphic (80.5\%). Resolving powers of the AFLP primers ranged from 0.410 to 0.942 making a total of 5.015, whereas the polymorphic information content ranged from 0.662 to 0.898 with an average of 0.812 . Unweighted pair-group method of arithmetic mean (UPGMA) clustering of the accessions showed three major groups representing $M$. nigra, $M$. rubra, and $M$. alba accessions. The $M$. alba group had two subgroups that were not correlated with fruit color. The UPGMA dendrogram of average taxonomic differences confirmed these results. The principle coordinate analysis demonstrated that $M$. nigra accessions had limited genetic variation. In conclusion, our study indicated that $M$. nigra and $M$. rubra are molecularly distinct from $M$. alba. Our results also suggest that $M$. nigra accessions having a low level of morphological variation are molecularly similar.
\end{abstract}

Mulberry is distributed in a wide area of tropical, subtropical, and temperate zones in Asia, Europe, North America, South America, and Africa. The trees historically have been used for sericulture especially in east, central, and south Asia. There are at least 24 species with more than 100 known cultivars (Koidzumi, 1917). Among them, only a few species of mulberry are valued for their edible fruit (M. alba, M. nigra, M. rubra, M. indica Linn., and M. laevigata L.) (Awasthi et al., 2004). Multiple fruits of the black mulberry (M. nigra) become dark red-black at maturity. The red mulberry ( $M$. rubra), native to eastern North America, has red to black fruits. Different white mulberry ( $M$. alba) genotypes have white, purple, or red color fruits. The mulberry fruits are sweet but they are very perishable. The fruit of $M$. nigra has a distinct flavor with juicy and acidic characteristics making them attractive for use in the processing industry in products such as fruit juice, ice cream, jelly, and jam. Other mulberry species are also used for making traditional foods such as "pekmez," "pestil," and "kome."

Received for publication 21 Apr. 2008. Accepted for publication 19 May 2008. Some of the leaf samples were supplied from the members of a project supported by The Scientific and Technological Research Council of Turkey (TÜBITTAK) (Project no.: TOVAG-106O102).

We thank TÜBITAK and everyone who contributed for the collection of these samples.

${ }^{1}$ Correspoinding author. E-mail: skafkas@mail.cu.edu.tr.
Mulberry species have been known and cultivated in Turkey for more than 400 years (Ercisli and Orhan, 2007). Cultivated genotypes for fruit production have primarily been developed from $M$. alba, M. nigra, and M. rubra, although $M$. alba is the dominant species in cultivation (95\%) (Ercisli, 2004). There are many local accessions but no named cultivars present in different parts of Turkey. The chemical composition of white, red, and black mulberry fruits sampled from the East Anatolia region of Turkey was previously investigated (Ercisli and Orhan, 2007). Orhan et al. (2007) also studied the relationship of $15 \mathrm{M}$. alba accessions sampled from Erzurum province using random amplified polymorphic DNA (RAPD) markers. However, mulberry accessions were not sampled in Turkey from wide ranges of region/provinces containing all three Morus species.

Molecular markers have been commonly used to characterize mulberry cultivars and wild accessions. For example, RAPD and intersimple sequence repeat (ISSR) markers were used to study the genetic relationships of Japanese and Indian cultivars to assess molecular variability (Vijayan, 2004; Vijayan et al., 2004a). ISSRs were also combined with simple sequence repeat (SSR) to reveal genetic variation among wild and cultivated mulberry species (Zhao et al., 2007a). Indeed, ISSRs have been the most common marker system used in mulberries (Kar et al., 2008; Vijayan and Chatterjee, 2003; Vijayan et al., 2004b, 2004c, 2006; Zhao et al., 2006, 2007b). 
Single primer amplification reactions were also used to characterize 27 mulberry cultivars (Bhattacharya et al., 2005).

Among polymerase chain reaction (PCR)-based molecular markers, amplified fragment length polymorphisms (AFLPs) are highly reproducible multilocus marker system developed by Vos et al. (1995). This method has several advantages over previously introduced methods such as RAPDs and ISSRs and has been extensively used for a wide range of species. High levels of polymorphism and high degrees of discriminative capacity are the main advantages of AFLPs for closely related accessions. Standard AFLP methods based on two cutting enzymes require labeling of selective primers, which necessitates the use of isotopes or fluorescent dyes.

Although the AFLP method has been used to identify genetic variability of many different plant species, the use of this powerful and reliable method in mulberries has been very limited. Molecular studies conducted by AFLPs have been limited to assessing genetic diversity in a mulberry germplasm collection (Sharma et al., 2000) identifying the origin of introduced mulberry accessions in Italy (Botton et al., 2005) and analyzing artificial triploid mulberries (Wang and $\mathrm{Yu}, 2001$ ). The objectives of this study were to characterize 43 accessions of M. alba, M. nigra, and M. rubra from Turkey using AFLP markers to determine whether AFLP markers are appropriate for this subgroup of Morus germplasm and to have a better understanding about the taxonomical relationships among these three species.

\section{Materials and Methods}

Plant materials. Cultivated mulberry genotypes of $M$. nigra [black mulberry (33 accessions)], M. rubra [red mulberry (5 accessions)], and M. alba [white- and purple-fruited mulberry ( 5 accessions)] were sampled across Turkey. Distribution of origin and location of trees for these genotypes are displayed in Table 1. Four of seven ecogeographical regions of Turkey were represented: Black Sea (3 accessions), Central Anatolia (15 accessions), Eastern Anatolia (10 accessions), and Mediterranean (17 accessions).

DNA EXTRACTION AND AFLP ANALYSIs. Genomic DNA was extracted from leaf tissue by the CTAB method of Doyle and Doyle (1987) with minor modifications (Kafkas et al., 2005). Concentration of extracted DNA was estimated by comparing band intensity with $\lambda$ DNA of known concentrations after $0.8 \%$ agarose gel electrophoresis and ethidium bromide staining. DNA was diluted to $50 \mathrm{ng} \cdot \mu \mathrm{L}^{-1}$ for AFLP reactions.

Details of AFLP assay, adaptor and primer sequences, PCR conditions for preselective and selective amplifications, and selective primer designation were according to Vos et al. (1995). Genomic DNA was restricted with EcoRI/MseI enzyme combination and double-stranded adaptors specific to each site were ligated. Preselective amplification was carried out with primers complementary to the adaptors with an extra selective base on each primer (EcoRI-A/MseI-C). Selective amplification was performed with eight primer combinations involving three $M s e \mathrm{I}(\mathrm{M})$ and three EcoRI (E) primers $\left(\mathrm{E}_{\mathrm{AAG}} / \mathrm{M}_{\mathrm{CAC}}\right.$, $\mathrm{E}_{\mathrm{AAG}} / \mathrm{M}_{\mathrm{CCA}}, \mathrm{E}_{\mathrm{AAG}} / \mathrm{M}_{\mathrm{CCG}}, \mathrm{E}_{\mathrm{ACC}} / \mathrm{M}_{\mathrm{CAC}}, \mathrm{E}_{\mathrm{ACC}} / \mathrm{M}_{\mathrm{CCT}}, \mathrm{E}_{\mathrm{ACC}} /$ $\left.\mathrm{M}_{\mathrm{CGA}}, \mathrm{E}_{\mathrm{AGC}} / \mathrm{M}_{\mathrm{CCC}}, \mathrm{E}_{\mathrm{AGG}} / \mathrm{M}_{\mathrm{CCC}}\right)$. Fragments were resolved using capillary electrophoresis on an ABI 3130 Genetic Analyzer [Applied Biosystems (ABI), Foster City, CA] with the data collection software 3.0 (ABI). AFLP fragment analysis was performed with GeneScanAnalysis Software 4.0 (ABI) and the data were assembled in binary format.
Table 1. Genotype codes, fruit colors, and origins of 43 accessions of three Morus species from nine provinces representing three ecoregions in Turkey.

\begin{tabular}{|c|c|c|}
\hline Accession code & Turkish province & Turkish ecoregion \\
\hline \multicolumn{3}{|c|}{ Morus nigra (black mulberry) } \\
\hline N4 & Adana & Mediterranean \\
\hline N9 & Kahramanmaraş & Mediterranean \\
\hline N10 & Kahramanmaraş & Mediterranean \\
\hline N11 & Kahramanmaraş & Mediterranean \\
\hline N12 & Kahramanmaraş & Mediterranean \\
\hline N14 & Antakya & Mediterranean \\
\hline N16 & Antakya & Mediterranean \\
\hline N18 & Antakya & Mediterranean \\
\hline N19 & Elazığ & Eastern Anatolia \\
\hline $\mathrm{N} 20$ & Elaziğ & Eastern Anatolia \\
\hline $\mathrm{N} 21$ & Elazığ & Eastern Anatolia \\
\hline N22 & Malatya & Eastern Anatolia \\
\hline $\mathrm{N} 24$ & Malatya & Eastern Anatolia \\
\hline $\mathrm{N} 25$ & Giresun & Black Sea \\
\hline $\mathrm{N} 28$ & Giresun & Black Sea \\
\hline N29 & Giresun & Black Sea \\
\hline N30 & Erzincan & Eastern Anatolia \\
\hline N32 & Erzincan & Eastern Anatolia \\
\hline N35 & Erzincan & Eastern Anatolia \\
\hline N36 & Erzincan & Eastern Anatolia \\
\hline N37 & Erzincan & Eastern Anatolia \\
\hline N44 & Tokat & Central Anatolia \\
\hline N45 & Tokat & Central Anatolia \\
\hline N48 & Tokat & Central Anatolia \\
\hline N49 & Tokat & Central Anatolia \\
\hline N52 & Tokat & Central Anatolia \\
\hline N55 & Tokat & Central Anatolia \\
\hline N56 & Tokat & Central Anatolia \\
\hline N60 & Tokat & Central Anatolia \\
\hline N61 & Amasya & Central Anatolia \\
\hline N62 & Amasya & Central Anatolia \\
\hline N63 & Amasya & Central Anatolia \\
\hline N68 & Amasya & Central Anatolia \\
\hline \multicolumn{3}{|c|}{ Morus rubra (red mulberry) } \\
\hline $\mathrm{R} 1$ & Adana & Mediterranean \\
\hline $\mathrm{R} 2$ & Kahramanmaraş & Mediterranean \\
\hline R6 & Adana & Mediterranean \\
\hline R7 & Tokat & Central Anatolia \\
\hline $\mathrm{R} 8$ & Tokat & Central Anatolia \\
\hline \multicolumn{3}{|c|}{ Morus alba (white-fruited mulberry) } \\
\hline Aw1 & Adana & Mediterranean \\
\hline Aw2 & Adana & Mediterranean \\
\hline \multicolumn{3}{|c|}{ Morus alba (purple-fruited mulberry) } \\
\hline Ap2 & Kahramanmaraş & Mediterranean \\
\hline Ap3 & Adana & Mediterranean \\
\hline Ap5 & Tokat & Central Anatolia \\
\hline
\end{tabular}

Data ANALYsis. The ability of the most informative primer pairs to differentiate between the genotypes was assessed by calculating their resolving power (Rp) according to Prevost and Wilkinson (1999) using the formula $\mathrm{Rp}=\sum \mathrm{Ib}$, where $\mathrm{Ib}=1-$ $(2 \times|0.5-p|)$, and $\mathrm{p}$ is the proportion of the 69 accessions containing the I band. The polymorphism information content (PIC) of each marker was calculated using PIC $=1-\sum \mathrm{Pi}^{2}$ where $\mathrm{Pi}$ is the band frequency of the ith allele (Smith et al., 1997). Jaccard's similarity coefficients (Sneath and Sokal, 
1973) were calculated for all pairwise comparisons among the 43 Morus genotypes. A dendrogram was generated using NTSYSpc version $2.11 \mathrm{~V}$ (Exeter Software, Setauket, NY) (Rohlf, 2004) based on unweighted pair-group method of arithmetic mean (UPGMA) cluster analysis. For this dendrogram, the bootstrap values for the clusters were calculated by making 1000 replicates using PAUP program (Swofford, 1998). In addition to the dendrogram of the 43 genotypes, AFLP band frequencies were calculated for each of the four classes [M. nigra, M. rubra, M. alba (purplefruited), and M. alba (white-fruited)] based on the average taxonomic distance parameter. Cluster analysis using the UPGMA method was performed to construct a dendrogram from the distance matrix. The representativeness of both dendrograms was evaluated by estimating cophenetic correlation for the dendrograms and comparing it with the similarity matrix and similarity interval matrix using Mantel's matrix correspondence test (Mantel, 1967). The result of this test is a cophenetic correlation coefficient, $r$, indicating how well the dendrogram represents similarity data. The similarity matrix data were also subjected to principal coordinate (PCoA) analysis using the NTSYSpc (version 2.11V; Exeter Software, Setauket, NY). The genotypes were plotted on first three dimensions using the G3D procedure of SAS (version 6; SAS Institute, Cary, NC).

\section{Results and Discussion}

LEVEL OF POLYMORPHISM AND DISCRIMINATING CAPACITY OF THE AFLP PRIMER PAIRs. The eight primer combinations used to study the 43 Morus accessions generated a total of 416 bands (Table 2). The number of bands produced by each primer combination ranged from $35\left(\mathrm{E}_{\mathrm{AAG}} / \mathrm{M}_{\mathrm{CCA}}\right)$ to $90\left(\mathrm{E}_{\mathrm{ACC}} / \mathrm{M}_{\mathrm{CGA}}\right)$ with an average of 52 bands. Of 416 bands, 337 were polymorphic $(80.5 \%$ polymorphism). The percentage of polymorphic bands varied considerably among the primer combinations. For example, all of the 40 bands generated by $\mathrm{E}_{\mathrm{ACC}} / \mathrm{M}_{\mathrm{CCT}}$ were polymorphic, whereas the $\mathrm{E}_{\mathrm{AAG}} / \mathrm{M}_{\mathrm{CCA}}$ combination yielded $71.4 \%$ polymorphic bands.

When we attempted to characterize Turkish mulberry accessions representing $M$. alba, M. nigra, and $M$. rubra, the
Table 2. Number of AFLP bands, percentage of polymorphic bands, resolving power, and polymorphism information content in the DNA fingerprinting of mulberry accessions from three Morus species sampled across Turkey.

\begin{tabular}{lccccc}
\hline $\begin{array}{l}\text { AFLP primer } \\
\text { combinations }\end{array}$ & $\begin{array}{c}\text { Total } \\
\text { bands (no.) }\end{array}$ & $\begin{array}{c}\text { Polymorphic } \\
\text { bands (no.) }\end{array}$ & $\begin{array}{c}\text { Polymorphism } \\
(\%)\end{array}$ & $\begin{array}{c}\text { Resolving } \\
\text { power }\end{array}$ & $\begin{array}{c}\text { Polymorphism } \\
\text { information content }\end{array}$ \\
\hline $\mathrm{E}_{\mathrm{AAG}} / \mathrm{M}_{\mathrm{CAC}}$ & 40 & 31 & 77.5 & 0.445 & 0.891 \\
$\mathrm{E}_{\mathrm{AAG}} / \mathrm{M}_{\mathrm{CCA}}$ & 35 & 25 & 71.4 & 0.488 & 0.898 \\
$\mathrm{E}_{\mathrm{AAG}} / \mathrm{M}_{\mathrm{CCG}}$ & 57 & 45 & 78.9 & 0.410 & 0.896 \\
$\mathrm{E}_{\mathrm{ACC}} / \mathrm{M}_{\mathrm{CAC}}$ & 54 & 44 & 81.5 & 0.622 & 0.808 \\
$\mathrm{E}_{\mathrm{ACC}} / \mathrm{M}_{\mathrm{CCT}}$ & 40 & 40 & 100.0 & 0.942 & 0.662 \\
$\mathrm{E}_{\mathrm{ACC}} / \mathrm{M}_{\mathrm{CGA}}$ & 90 & 78 & 86.7 & 0.683 & 0.789 \\
$\mathrm{E}_{\mathrm{AAG}} / \mathrm{M}_{\mathrm{CCC}}$ & 50 & 36 & 72.0 & 0.742 & 0.753 \\
$\mathrm{E}_{\mathrm{AAG}} / \mathrm{M}_{\mathrm{CCC}}$ & 50 & 38 & 76.0 & 0.683 & 0.800 \\
Total & 416 & 337 & - & 5.015 & - \\
Mean & 52 & 42 & 80.5 & - & 0.812
\end{tabular}

$\overline{\mathrm{AFLP}}=$ amplified fragment length polymorphism.

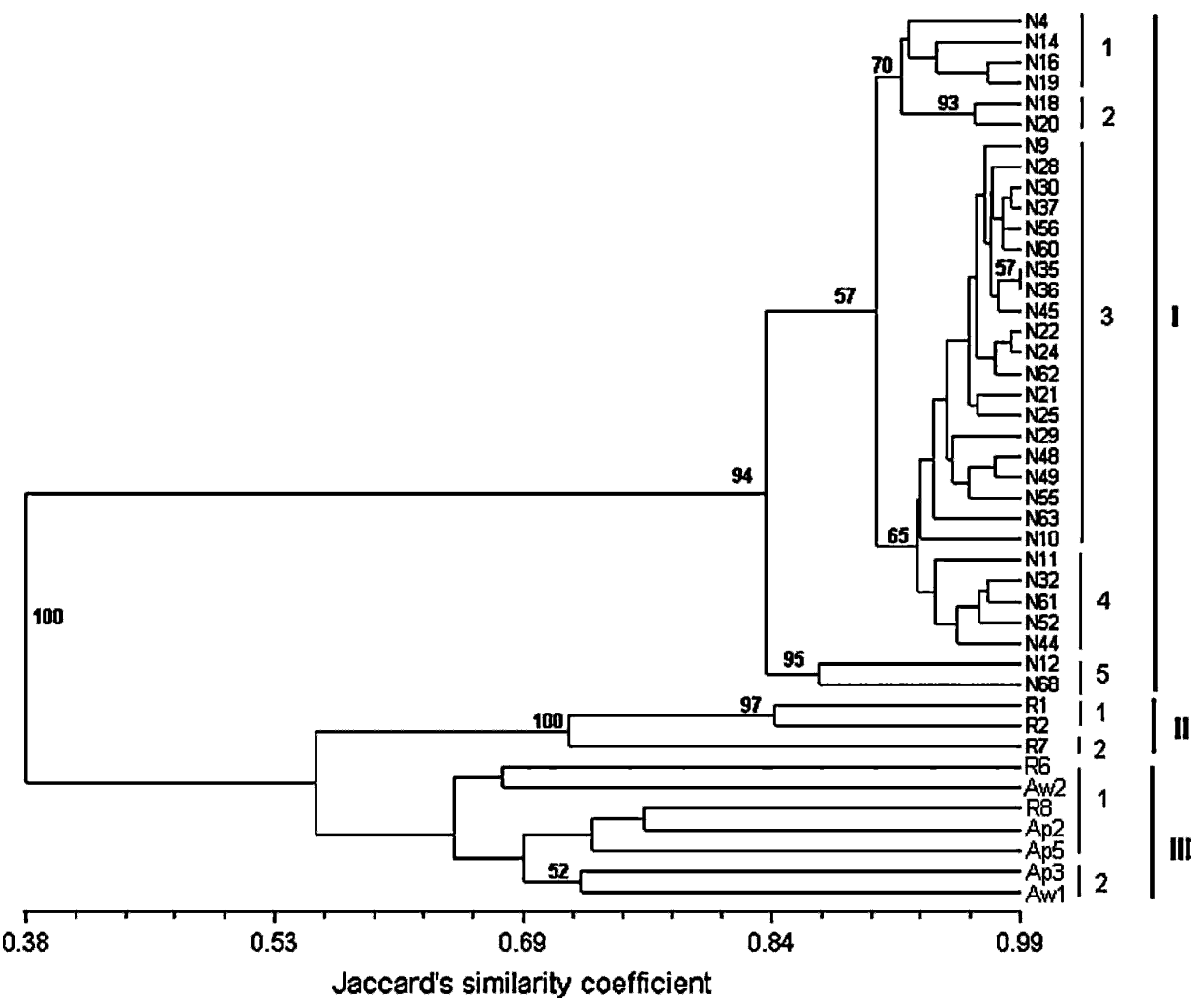

Fig. 1. Dendrogram of 43 mulberry genotypes from three Morus species resulting from the unweighted pair-group method of arithmetic mean cluster analysis based on Jaccard's similarity coefficient obtained from 416 amplified fragment length polymorphism markers. $r=0.99$ for goodness-of-fit. Only the nodes supported by greater than $50 \%$ bootstrap values were presented: $\mathrm{N}=$ Morus nigra (black mulberry); $\mathrm{R}=$ M. rubra (red mulberry); Aw $=$ M. alba (white-fruited mulberry); Ap = M. alba (purple-fruited mulberry).
AFLP analysis successfully differentiated the genotypes and it was confirmed that AFLP is a powerful marker system. AFLP markers have been previously used in the analysis of mulberry populations. Sharma et al. (2000) studied 43 mulberry accessions from ecogeographic regions of Japan and other parts of the world. In their collections, 21 species and $2 \times, 3 \times, 4 \times, 6 \times$, and $22 \times$ ploidy levels were presented. Each of five primer combinations they studied generated an average of 110 amplification products and their percentage of polymorphic bands ranged from 69.7 to 82.3 . Botton et al. (2005) characterized 
48 accessions from three species, M. alba, M. latifolia Poir., and M. bombycis Koidz. Their accessions originated from diverse regions of the world such as Italy, China, Japan, India, the Middle East, Philippines, and Brazil. In their study, they used six primer combinations and scored an average of 110 bands per combination, $72.2 \%$ of which were polymorphic. Although our accessions represent only three diploid species, all originating from Anatolia, their level of polymorphism was comparable to those of previous studies. This is an indication of the high degree of polymorphism among the accessions tested.

$\mathrm{Rp}$ values ranged from $0.410\left(\mathrm{E}_{\mathrm{AAG}} / \mathrm{M}_{\mathrm{CCG}}\right)$ to $0.942\left(\mathrm{E}_{\mathrm{ACC}}\right.$ $\mathrm{M}_{\mathrm{CCT}}$ ) with a total of 5.015. The PIC values of the primer combinations ranged from 0.662 to 0.898 with an average of 0.812 . The PIC values we recovered in this study were much higher than those of Zhao et al. (2007a) in which they studied 27 mulberry accessions from several Morus species by 15 SSR primers generating 138 reliable bands, $91.3 \%$ of which were polymorphic.

GENETIC RELATEDNESS AMONG THE MoRUS SPECIES AND ACCESSIONS. A dendrogram was obtained by the UPGMA method using the total number of AFLP bands (Fig. 1). There were three groups in the dendrogram. Group I consisted of $M$. nigra accessions. Indeed, all $M$. nigra accessions were grouped in this cluster and the node separating these accessions from the others were highly supported by the bootstrap value $(100 \%)$. This indicates that $M$. nigra is distinct from the other species studied. Another dendrogram was generated using frequency data within the entries (Fig. 2). This dendrogram, exhibiting average taxonomic difference, also confirmed the distinctness of $M$. nigra. The same conclusion can be made from Figure 3 showing the results of PCoA. The bootstrap values supported some of the nodes within Group I (Fig. 1); based on these values, five subgroups were identified. However, PCoA failed to clearly separate $M$. nigra accessions, indicating that they had limited levels of molecular variation. Indeed, although M. nigra accessions were sampled from various ecological conditions, they displayed only limited morphological variation for many horticultural traits (data not presented).

Three M. rubra accessions (R1, R2, and R7) formed Group II, although two other M. rubra accessions (R6 and R8) were grouped among the $M$. alba accessions (Fig.
1). The bootstrap values further separated Group II into two subgroups. PCoA revealed the same results (Fig. 3). The dendrogram constructed from average taxonomic differences supported the separation of M. rubra from M. alba (Fig. 2).

The third group in the UPGMA dendrogram consisted of all of the M. alba accessions along with two M. rubra accessions (Fig. 1). The bootstrap values separated the accessions of Group II into two subgroups. However, this separation was not highly supported (52\%) and not based on fruit color (white- versus purple-fruited). The dendrogram exhibiting average taxonomic differences of entries (Fig. 2) and the PCoA (Fig. 3) analyses were also not successful in differentiating white- and purplefruited M. alba accessions.

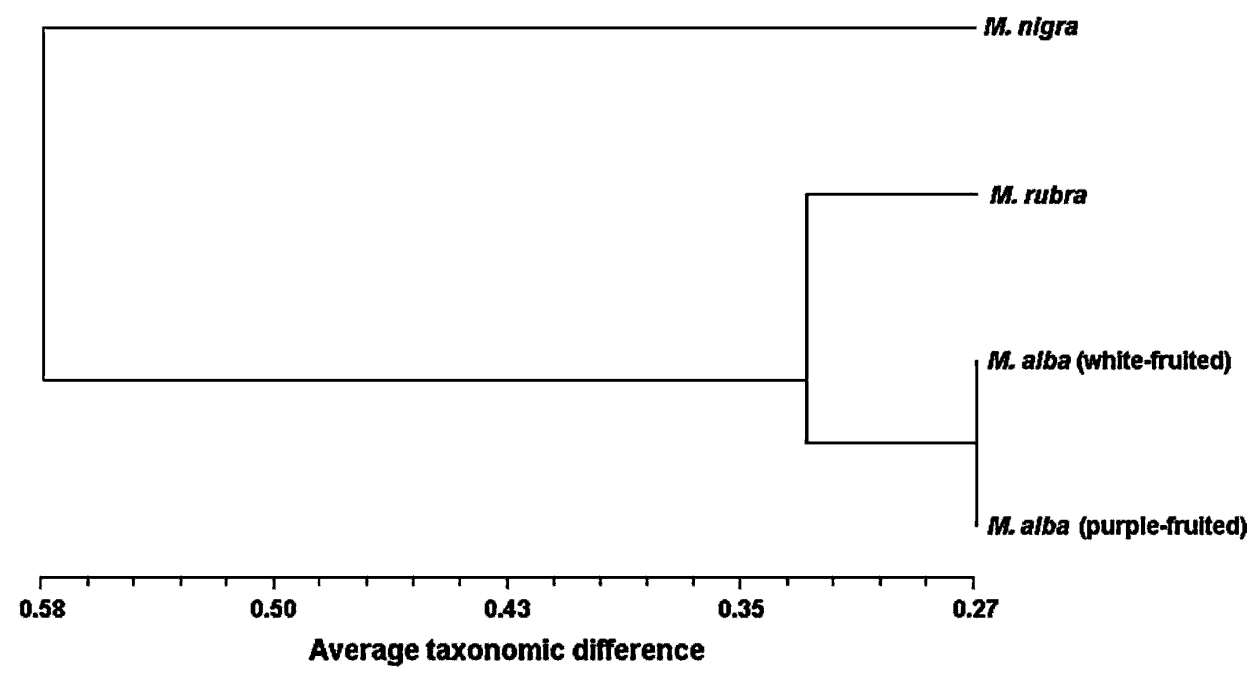

Fig. 2. Dendrogram of four mulberry classes from three Morus species resulting from the unweighted pair-group method of arithmetic mean cluster analysis based on average taxonomic differences of amplified fragment length polymorphism band frequencies within taxonomic classes. $r=0.99$ for goodness-of-fit.

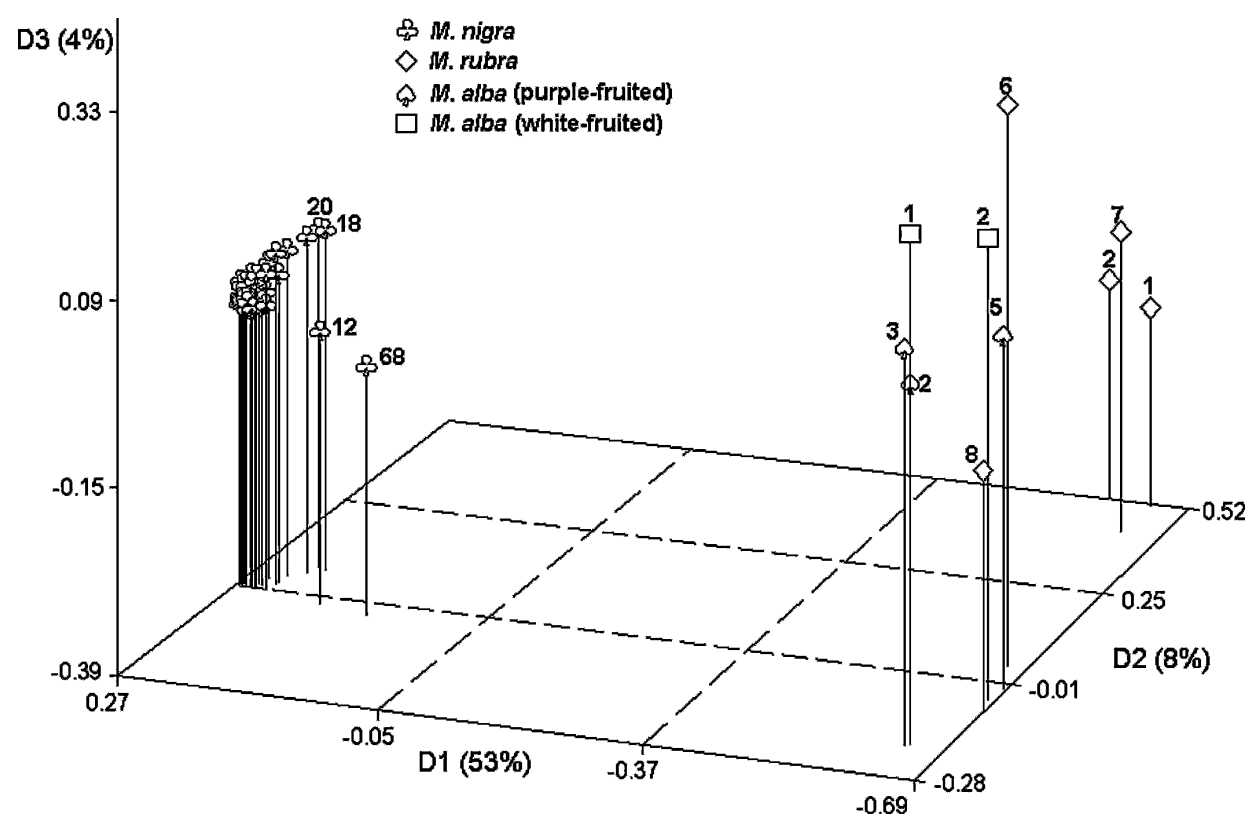

Fig. 3. Principle coordinate analysis of 43 mulberry genotypes from three Morus species resulting from analysis of 416 amplified fragment length polymorphism markers. Only a few of the M. nigra genotypes were labeled because they were closely clustered in the figure. 
The UPGMA dendrogram of AFLP bands even separated the closely related $M$. nigra accessions. Thus, our results were in general agreement with those of Sharma et al. (2000) and Botton et al. (2005). In our analyses, the accessions were most tightly clustered by their species and there were no apparent interrelationships based on the origin of the accessions. Regarding Morus taxonomy, our analysis shed light into relationships of $M$. alba, M. nigra, and M. rubra. Our results indicated that $M$. nigra is distinct from the other species. Previous studies on the relationships of the Morus species conducted by AFLP came to the same conclusion. Sharma et al. (2000) and Botton et al. (2005) used a representative of $M$. nigra that was found distinct from $M$. alba and $M$. nigra accessions. In fact, the $M$. nigra accession of Botton et al. (2005) was different from all other entries in their study. In the study of Zhao et al. (2007b), a representative of M. nigra was also separated from all the cultivated accessions studied.

The results of the present study may benefit breeders in selecting the most diverse genotypes with similar fruit characteristics to begin crossing and selection programs. This may result in increased mulberry growing for fruit production rather than just sericulture.

\section{Literature Cited}

Awasthi, A.K., G.M. Nagaraja, G.V. Naik, S. Kanginakudru, K. Thangavelu, and J. Nagaraju. 2004. Genetic diversity and relationships in mulberry (genus Morus) as revealed by RAPD and ISSR marker assays. BMC Genet. 15 Mar. 2008. <http://www.biomedcentral. com/1471-2156/5/1>.

Bhattacharya, E., S.B. Dandin, and S.A. Ranade. 2005. Single primer amplification reaction methods reveal exotic and indigenous mulberry varieties are similarly diverse. J. Biosci. 30:669-677.

Botton, A., G. Barcaccia, S. Cappellozza, R. Da Tos, C. Bonghi, and A. Ramina. 2005. DNA fingerprinting sheds light on the origin of introduced mulberry (Morus spp.) accessions in Italy. Genet. Resour. Crop Evol. 52:181-192.

Doyle, J.J. and J.L. Doyle. 1987. A rapid isolation procedure for small quantities of fresh leaf tissue. Phytochem. Bul. 19:11-15.

Ercisli, S. 2004. A short review of the fruit germplasm resources of Turkey. Genet. Resour. Crop Evol. 51:419-435.

Ercisli, S. and E. Orhan. 2007. Chemical composition of white (Morus alba), red (Morus rubra) and black (Morus nigra) mulberry fruits. Food Chem. 103:1380-1384.

Kafkas, S., H. Ozkan, and M. Sutyemez. 2005. DNA polymorphism and assessment of genetic relationships in walnut genotypes based on AFLP and SAMPL markers. J. Amer. Soc. Hort. Sci. 130:585-590.

Kar, P.K., P.P. Srivastava, A.K. Awasthi, and S.R. Urs. 2008. Genetic variability and association of ISSR markers with some biochemical traits in mulberry (Morus spp.) genetic resources available in India. Tree Genet. Genomes 4:75-83.

Koidzumi, G. 1917. Taxonomy and phytogeography of the genus Morus. Bul. Sericulture Expt. Station 3:1-12.

Mantel, N. 1967. The detection of disease clustering and a generalized regression approach. Cancer Res. 27:175-178.

Orhan, E., S. Ercisli, N. Yidirim, and G. Agar. 2007. Genetic variations among mulberry genotypes (Morus alba) as revealed by random amplified polymorphic DNA (RAPD) markers. Plant Syst. Evol. 265:251-258.
Prevost, A. and M.J. Wilkinson. 1999. A new system of comparing PCR primers applied to ISSR fingerprinting of potato cultivars. Theor. Appl. Genet. 98:107-112.

Rohlf, F.J. 2004. NTSYS-pc numerical taxonomy and multivariate analysis system. Version 2.11V. Exeter Software, Setauket, NY.

Sharma, A., R. Sharma, and H. Machii. 2000. Assessment of genetic diversity in a Morus germplasm collection using fluorescence-based AFLP markers. Theor. Appl. Genet. 101:1049-1055.

Smith, J.S.C., E.C.L. Chin, H. Shu, O.S. Smith, S.J. Wall, M.L. Senior, S.E. Mitchell, S. Kresovich, and J. Ziegle. 1997. An evaluation of the utility of SSR loci as molecular markers in maize (Zea mays L.): Comparisons with data from RFLPs and pedigree. Theor. Appl. Genet. 95:163-173.

Sneath, P.H.A. and R.R. Sokal. 1973. Numerical taxonomy: The principles and practice of numerical classification. Freeman, San Francisco, CA.

Swofford, D.L. 1998. PAUP: Phylogenetic analysis using parsimony (and other methods). Version 4. Sineauer Associates, Sunderland, MA.

Vijayan, K. 2004. Genetic relationships of Japanese and Indian mulberry (Morus spp.) genotypes revealed by DNA fingerprinting. Plant Syst. Evol. 243:221-232.

Vijayan, K. and S.N. Chatterjee. 2003. ISSR profiling of Indian cultivars of mulberry (Morus spp.) and its relevance to breeding programs. Euphytica 131:53-63.

Vijayan, K., A.K. Awasthi, P.P. Srivastava, and B. Saratchandra. 2004a. Genetic analysis of Indian mulberry varieties through molecular markers. Hereditas 141:8-14.

Vijayan, K., P.K. Kar, A. Tikader, P.P. Srivastava, A.K. Awasthi, and B. Saratchandra. 2004b. Molecular evaluation of genetic variability in wild populations of mulberry (Morus serrata Roxb.). Plant Breed. 123:568-572.

Vijayan, K., P.P. Srivastava, and A.K. Awasthi. 2004c. Analysis of phylogenetic relationship among five mulberry (Morus) species using molecular markers. Genome 47:439-448.

Vijayan, K., A. Tikader, P.K. Kar, P.P. Srivastava, A.K. Awasthi, K. Thangavelu, and B. Saratchandra. 2006. Assessment of genetic relationships between wild and cultivated mulberry (Morus) species using PCR based markers. Genet. Resour. Crop Evol. 53:873-882.

Vos, P., L. Hogers, M. Bleeker, T. Van De Lee, M. Hornes, A. Frijters, J. Pot, J. Peleman, M. Kuiper, and M. Zabeau. 1995. AFLP: A new technique for DNA fingerprinting. Nucleic Acids Res. 23:4407-4414. Wang, Z.W. and M. Yu. 2001. AFLP (amplified fragment length polymorphism) analysis of genetic background of polyploid breeding materials of mulberry (Morus alba L.). Acta Sericologic Sinica 27:170-176.

Zhao, W.G., Z.H. Zhou, X.X. Miao, S.B. Wang, L. Zhang, Y.L. Pan, and Y.P. Huang. 2006. Genetic relatedness among cultivated and wild mulberry (Moraceae: Morus) as revealed by intersimple sequence repeat analysis in China. Can. J. Plant Sci. 86: 251-257.

Zhao, W.G., Z.H. Zhou, X.X. Miao, Y. Zhang, S.B. Wang, J.H. Huang, H. Xiang, Y.L. Pan, and Y.P. Huang. 2007a. A comparison of genetic variation among wild and cultivated Morus species (Moraceae: Morus) as revealed by ISSR and SSR markers. Biodivers. Conserv. 6:275-290.

Zhao, W., Y. Wang, T. Chen, G. Ra, X.M. Wang, J.L. Qi, Y.J. Pang, S.S. Wang, Z.H. Li, Y.P. Huang, Y. Pan, and Y.H. Yang. 2007b. Genetic structure of mulberry from different ecotypes revealed by ISSRs in China: An implications for conservation of local mulberry varieties. Scientia Hort. 115:47-55. 